Homelessness workers negotiating the relationship between identity and practice: how gender, age and background influence workerservice user relationship

Jennifer Galbraith, University of Stirling - jennifer.galbraith@stir.ac.uk

ORCID - https://orcid.org/0000-0003-1774-7963

This is an Accepted Manuscript of an article published by Taylor \& Francis Group in Housing, Theory and Society on 1 Mar 2019, available online:

http://www.tandfonline.com/10.1080/14036096.2019.1584585. 


\title{
Homelessness workers negotiating the relationship between identity and practice: how gender, age and background influence worker-service user relationship
}

\begin{abstract}
The relationships people who are homeless form with homelessness workers influence how successfully they navigate the homelessness system. Despite relationships being comprised of two or more people, research often focuses on the experiences of people who are homeless, neglecting the experiences of workers. Using interviews with 15 workers from homeless hostels across the Scottish Central Belt, this study explored how their identities, experiences and beliefs influenced their practice and relationships with residents. Theories of impression management, gender performativity, intersectionality, and 'use of self' formed a framework to inform the analysis. The analysis revealed that gender, age and background impacted practice and relationships, both positively and negatively, with residents and fellow workers. Interviewees also discussed ways in which they explicitly addressed these factors in their practice. The findings suggest that training programmes, such as roleplay, should be devised which acknowledge the implications of gender, age and background on worker-service user relationships.
\end{abstract}

Key words: homeless, identity management, identity, identity formation, relationships

\section{Introduction}

There have been many studies centring on the experiences of people who are homeless and their relationships with services (see Snow and Anderson, 1987: Robinson, 2008: Bhui et al, 2006: Huey and Berndt, 2008: Stevenson, 2013). Comparatively few studies have been conducted on the homelessness workers' experiences and how they perceive their relationships with people who are homeless. For workers on the front line of homelessness assistance, the ability to foster and maintain a strong relationship can play an integral role in assisting people who are homeless to successfully navigate the process of looking for housing and employment (Centre for Economic and Social Inclusion, 2006). However, building such relationships relies not only on workers managing their own perceptions, but how the people who are homeless perceive the workers (Zufferey, 2009). Internationally, research exploring how homelessness workers' practice and relationships can be influenced by perceptions of their identities is sparse, and largely revolves around the practice of social workers (Zufferey, 2009). The predominance of social workers operating in homelessness services internationally lowers the applicability and transferability of this literature to the UK because, due to the Housing (Homeless Persons) Act 1977, the responsibility for homelessness services within the UK has been transferred from social work to housing departments (Crown, 1977: Lund, 2010: Anderson and Serpa, 2013). Under the Housing (Scotland) Act 2010 social workers are mainly involved in homelessness services if a person has additional issues, such as mental health, that may or may not be connected to their homelessness (Crown, 2010). In brief, only being homeless is not a reason to have a social worker, and so at present UK homelessness workers - e.g. hostel workers - are not always social work trained (Scottish Government, 2013: Lund, 
2011: Fitzpatrick et al, 2000: Manthorpe et al, 2013: Crown, 2010). Whilst homelessness social workers in international studies conduct similar duties to homelessness workers within the UK, social workers have more formalised training (Scottish Government, 2005). Therefore even though social work literature can give useful insights and is considered later in this article, it will not be completely applicable to the UK context. Since homelessness workers in the UK do not necessarily come from a social work background there is a need to explore how they negotiate their identities in the workplace and how this impacts relationship building. This paper aims to contribute to this area by reviewing the existing literature documenting how homelessness workers identities can influence their practice and their identity as a professional, as well as their relationships with people who are homeless. It will then discuss the findings and implications generated from a study undertaken between November 2015 and August 2016 that explored how homelessness workers identities impacted their practice and relationships and strategies they formed in response to this.

\section{Homelessness workers identities - influencing practice}

Homelessness workers in the UK have a responsibility to help people who are homeless gain settled housing and employment (Centre for Economic and Social Inclusion, 2006). Within temporary accommodation workers support residents in a number of ways, for example, gaining access to welfare, making applications for social housing, providing access to food and basic necessities, and assist residents in going to appointments. However, this description of their role neglects the daily interactions homelessness workers have with people who are homeless, and that for support to be as effective as possible a positive relationship needs to be formed. Whilst academic works, both in social work and homelessness, have addressed that workers identities and perceptions of their identities can affect practice, it is only mentioned in passing or alluded to (see Jardine and Bilton, 2006: Christie, 2006: Bhui et al, 2006). Furthermore, of the work that has been done, Stevenson (2013) states that most look at the interactions and relationships between staff and residents in temporary accommodation for young people, leaving adult homeless populations ignored.

Drawing on this limited evidence base, the current study was inspired by Carole Zufferey's (2009) work in Australia. This study analysed how social workers felt their gender, age, cultural origin, and work experience affected their practice with people who were homeless (Zufferey, 2009: 385). Within this research female workers reported that their gender affected their professional relationship with homeless men, as some men formed romantic attachments and made that apparent. One female social worker also reported she felt that because of her gender she had taken the role of mother with some of her younger male service users. As a result of this perception she felt they saw her as empathetic and caring and they frequently discussed their problems with her. Whilst not explicitly mentioned, from these examples it is clear that perceptions of these workers' gender impacted their abilities to form positive relationships. For example:

I am conscious ... like you have to be careful with guys; ... you kind of get this feeling. ... They are quite often your same age group. ... This guy that I go and see ... I am sure he is in love with me; ... nothing inappropriate has ever happened, ... but you have to be aware of that being a factor (Zufferey, 2009: 387-388, author added emphasis)

This shows how crucial perceptions of identity, in this case gender, can be in being able to provide effective support. However, people are made up of more than their gender, and one participant spoke of being less of a target through being perceived as non-threatening due to 
their combined stature and gender. This highlights how workers need to take into account multiple aspects of their identity and how they can be perceived in order to form positive relationships. All of those interviewed in Zufferey's (2009) study were aware of the invisible impact that power, gender, class, and culture had on their work in the homelessness field and how this could clash with their professional practice, yet how they coped with this was not discussed (Zufferey, 2009: Zufferey, 2015). Whilst this study provides useful insights, the differences in homelessness provision between the UK and Australia means the transferability is limited. Closer to the context of the current research, issues similar to those of Zufferey's (2009) participants were raised in Harding (2002). Harding's (2002) work documents a teaching initiative where her undergraduate students volunteered at a homelessness day centre in London and conducted interviews with service users. It must be noted that this article served to evaluate this teaching initiative, and was not designed to document how her students' identities impacted their relationships with service users. Regardless, it is evident that the identities of the students affected the likelihood of obtaining interviews. For example, due to being a student and being stereotyped as young and inexperienced the likelihood of obtaining an interview was thought to increase as there was less of a power disparity between the students and the homeless service users (Harding, 2002). In a similar vein to Zufferey (2009) female students reported male service users flirting with them during the course of volunteering (Harding, 2002). This resulted in uncomfortable situations whereby the female students had to decline the advances, potentially damaging that relationship (Harding, 2002). The one male student involved also reported feeling nervous interviewing a female service user due to the gender disparity in case she felt uncomfortable. As part of the students' induction, staff at the service mentioned that some of their female colleagues had also received sexist gestures and comments (Harding, 2002). Despite these hints at clashes due to identity, how these interpretations of the students and staffs identities clashed with the professional role they were enacting and how this affected the relationships were not explored in the paper. Furthermore, Harding (2002) focused on her students and largely discussed how their identities impacted their garnering of interviews. The students had only assumed the role of day centre volunteers for a brief period of time meaning this study cannot be said to be representative of the experiences of full-time homelessness workers in the UK.

Overall, despite being insightful these studies provide a limited indication of how homelessness workers identities can impact their practice, their relationships with people who are homeless and their subsequent outcomes. This paper builds on these insights from the literature to provide a more in-depth exploration of identity management practices in homelessness services in the Scottish context.

\section{Theorising identity}

It has already been determined that relationships can be influenced both positively and negatively by how one's identity is perceived and negotiated. The definition of identity used in the current study was generated from the theories of Erving Goffman, Judith Butler, and Kimberlé Crenshaw.

Goffman's (1959) impression management is where social actors present versions of their identity depending on the context of their interaction (Goffman, 1959). Identity is a performance, with social actors performing a particular role to a set of observers (McCarthy, 2013: Goffman, 1959). The "expressive equipment" that is consciously or unconsciously used in these performances was termed a front by Goffman (Goffman, 1959: 32). Goffman also developed the idea of social fronts which are comprised of Setting, Appearance, and Manner. Setting is the context for the interaction - e.g. a living room - involving furniture, décor etc. and is where the performer begins their performance. Appearance consists of fixed attributes 
like age or ethnicity that are visually evident to the observer and denote the role they are taking at that point in time. Manner is the attitudes the performer expresses which indicate the role in which they are taking in the interaction - e.g. haughty, aggressive etc. (Goffman, 1959: 32-35). The latter two were termed as personal fronts which are composed of fixed and unfixed attributes such as clothing, gender, age, ethnicity, physicality, language etc. and both are expected to correlate to one another. These personal fronts can be altered in order to manage the impression that one gives through either concealing or emphasising aspects of their identity (Goffman, 1959). Language is a good example of this with individuals adapting their language patterns depending on the social environment in which they are in to position them as an insider or an outsider (Langlotz, 2015: Goffman, 1959). However, some personal fronts such as ethnicity are relatively fixed and cannot be changed as easily (Goffman, 1959).

Although identity is more complex than someone consciously altering their identity to change the impression they exude, and so the work of Judith Butler can address this. Butler (1999) viewed identity performance as unconscious, constructed through social interaction with others and the perceptions that we have of ourselves during those interactions. However, to use gender as an example, gender identity is not static and is also influenced by age as humans grow. A female identity can be constructed as a girl early in the life course and as she grows older she can then be labelled a woman, creating different expectations and restrictions. For example, the situation with the worker in Zufferey's (2009) study who felt she had taken on a mothering role would not have arisen had she been younger than the resident in question. Within that interaction, her age coupled with her gender combined to create a different perception of her identity than that which would have been placed on a younger woman. Through unconsciously reproducing and performing within these expectations and restrictions, gender becomes an ingrained part of an individual's identity. Certain performances being embedded in society can also generate stereotypes. Abrams et al (2015) define stereotypes as being composed of assumptions around attributes people should hold as a result of their personal characteristics, such as gender and age. For example, older figures can be regarded as dominant and wise; younger individuals can be regarded as more competent, women can be seen as warm and caring and men as being strong (Abrams et al, 2015: Masip et al, 2004: Eisenchlas, 2013).

It is not as simple to say that one consciously and unconsciously performs identity, instead one consciously and unconsciously performs multiple identities simultaneously (Butler, 1999: Goffman, 1959). Intersectionality recognises that people have multiple identities that interact to influence ones opportunities and disadvantage (Crenshaw, 1989: Crenshaw, 1991). For example, in Zufferey (2009) an older female social worker professed feeling like a mother due to the intersection of her age and gender. In reporting this if Zufferey (2009) divorced gender from age and reported them as separate instead of interacting, then it would only be a partial account of their experiences.

Drawing from these theories, identity is defined within the current study as a fluid entity, whereby individuals possess multiple identities simultaneously which, though ingrained, are not inherent but created through social interaction consciously and subconsciously, and can be manipulated if recognised by the individual. This definition highlights how complex the social relations are between social actors, as various aspects of identity come into play within interactions that create different impressions and subsequently impact relationships. Being aware of this and managing one's identity is integral to homelessness workers fostering relationships with people who are homeless and producing positive housing outcomes (Centre for Economic and Social Inclusion, 2006). Further to this, according to the 'use of self' literature in social work, workers can draw on personal aspects as well professional to actively build positive relationships and support (Gordon and Dunworth, 2017). Davies (1994) states workers 'self' as: 
'an identifiable person [...] her idiosyncrasies [...] her height, her age, her sex, her ethnic origins, her temper, her energy, her prejudices - these are the qualities she has to work with, for better or worse' (Davies, 1994: 174:175)

Workers can utilise these aspects to build relationships and achieve positive outcomes for clients (Davies, 1994). In this vein, it has been highlighted in social work literature that clients have preferred social workers who are knowledgeable, but who can also relate to them on a personal level (see Beresford et al, 2008: de Boer and Coady, 2006). However, in the field of homelessness existing research scarcely discussed how homelessness workers specifically negotiate and modify their identities and 'selves' to aid their practice and form positive relationships with people who are homeless. Therefore, the present study seeks to explore how homelessness workers negotiate perceptions of their identities to aid positive relationship building with people who are homeless. Inspired largely by the work of Carole Zufferey, it sought to determine if homelessness workers' gender, age and background affected their relationships with people who are homeless.

\section{Data and Methods}

The current qualitative study was conducted between November 2015 and August 2016 and funded by the Economic and Social Research Council (ESRC). 15 homelessness workers were purposively recruited (Matthews and Ross, 2012) through contacting five temporary accommodation hostels across the Central Belt of Scotland. The participants first completed a questionnaire and then participated in a semi-structured interview where the interview schedule was informed by their answers to the questionnaire. The sample comprised of 7 men and 8 women with the average length of time working in the homelessness sector being 7.4 years, but ranging from 1 year to 14 years. Five of the participants were aged between 18-34, nine were aged between 35-54 and one was aged over 55 years old.

\section{Questionnaire:}

Firstly the research utilised a questionnaire to gather background information on the 15 participants and generate topics that then were used for the semi-structured interviews. The questionnaire deductively covered scenarios that could arise in working in temporary accommodation (e.g. aggressive residents) and if they felt their gender, age or background impacted the scenarios. It was decide to start with gender, age, and background since these were the main issues identified in Zufferey (2009). More inductive questions were then asked inviting participants to expand and suggest other scenarios or aspects of identity that impacted relationships. The questionnaires were only used in the analysis to gain demographic data in this work as the sample size was small and the sparse data collected was expanded within interviews.

\section{Interviews:}

Semi-structured interviews were conducted as a follow up to the questionnaires. The final 22 interview questions included enquiries around the workers' gender, age and background that were generated from the literature and corroborated by the questionnaires as key issues, and how they felt perceptions of these by residents influenced their practice and relationships with 
residents and how they responded to this. There was also space left at the end of the interview schedule to allow participants to expand on any other issues outside of gender, age and background that had emerged in the questionnaires or over the course of the interviews. It is recognised that asking about gender, age and background in this way treats aspects of identity as separate and could be construed as a limitation. The interview schedule was designed in this way to provide focus with gender, age and background instigating the discussions and participants did make assertions which overlapped the three main themes. The data collection was staggered, with the interviews being conducted over a period of two months. This allowed for the incorporation of insights gleaned from previous interviews into the later ones.

\section{Analysis:}

For the main body of analysis, a coding framework was derived with the main codes (gender, age, and background) a priori taken from the interview schedule. The transcripts were then printed, read and highlighted in colours that represented the three main codes. Notes were written next to each highlighted section that detailed what was occurring in the text and the implications this had on the research (Bryman, 2012). After each transcript was completed in this way, a summary was written up consolidating the notes made into sub-codes under gender, age, and background. Miscellaneous and faith were also created as main codes during this process where purpose of the former was to encapsulate elements of interest that did not fit into the other three main codes and the latter was amalgamated into background during the analysis. The codes were arranged hierarchically (Bryman, 2012) in NVivo with the sub-codes stemming from the main codes. Once the transcripts were uploaded they were coded under the sub-codes of each of the main codes. Once this was completed each of the sub-codes was analysed thematically, looking for similarities and differences in the accounts, before writing the most prominent up and linking the data to the theoretical framework of identity and previous literature (Bryman, 2012).

\section{Ethical Considerations:}

Ethical approval was received from the University ethics committee in November 2016. Allowing no harm to come to the researcher and the participants was paramount and the research took place in accordance with the SRA's (2003) guidelines. Interviews took place in the hostels, in rooms accessible to workers and the researcher - not residents. Participants kept radios/phones nearby should they be required to deal with an incident, and if this was the case the interview was paused. The researcher was also given a radio if they went anywhere in the building without a worker present. Continual consent was utilised, with participants being asked for consent to the research in the questionnaire, full consent form and before interviews (Farrimond, 2013).

\section{Results and Discussion}

The analysis will be presented in three sections, with each section focusing on the three main codes (gender, age and background respectively). Due to the fluid and complex nature of identity, containing subthemes within the sections was difficult in some cases (e.g. where age and gender were influencing interactions in tandem), and so those which clearly bridge across sections are used as leads from one section into another. 


\section{Gender}

With a third of participants mentioning it, flirting and overfamiliarity emerged as a key issue in regards to female workers maintaining a credible professional identity with residents. Participants reported residents adopting a more familiar manner, and one participant felt residents asked her more about her personal life than her male colleagues. She also noted that residents sometimes addressed her using terms of endearment - e.g. "princess" (Fiona) - and often made comments on her appearance. This resulted in feelings that both their professionalism and authority were being challenged, and hindered their rapport building and practice. Two female participants heavily mentioned being flirted with was uncomfortable as it drew attention to the idea that male residents viewed the female members of staff as attractive, and added a dimension to the relationship that had not previously been there, similar to views in Harding (2002) and Zufferey (2009). This view was encapsulated by the following participant:

So maybe before I'm interacting with them person to person, and I'm like, y'know, I'm enjoying having a joke with you or whatever, but now you've suddenly highlighted to me that you're attracted to me as a woman and I'm like, actually, I wasn't even, y'know, I had, I wasn't even comprehending that in terms of how we were interacting, and so, yeah, I think there's maybe an element of that then so like 'oh, right okay'. (Fiona)

From this highlighting of gender and attractiveness, the power dynamics and ability to maintain a professional role within the workplace became more difficult to negotiate in the eyes of participants. This in turn led to participants who had experienced this type of overfamiliarity adopting a more guarded and reserved attitude to the resident in question, and thus altering their practice and the relationship. The reasons behind forming this guarded and reserved attitude was explained by the following participant:

People think it's easier to comment on things about how you look, and things that you do. I'm sure I get more questions about whether or not I'm married, or more prying into my personal life than my male colleagues. [...] I feel like I have to be, put on a bit more of a front, a bit harsher, a bit more kinda steely, just to get their respect, so I'm not just a girl. (Elizabeth)

Participants also tried to change the impression they felt they projected as a result of being female through dressing in ways that did not highlight their gender. In this sense, in reaction to flirtation or inappropriate behaviour from residents, participants would intentionally, and sometimes unintentionally, alter their personal front and their 'self' (Davies, 1994). Illustrating with Goffman (1959) this would be Appearance in terms of their clothing, and their Manner in relation to their guarded demeanour - to give a different impression of gender and foster a more professional relationship. Along with these changes in demeanour and dress, verbally emphasising the inappropriateness of such behaviour was also thought to be an effective way of negating any future incidences from that resident.

Three participants mentioned noticing lack of engagement with female workers when working with residents who, it was believed, originated from cultures with different constructions of gender roles. It was felt by participants that this was due to not seeing women in a professional capacity due to their gender. Therefore, as Butler (1999) highlights, whilst we are socialised according to our genders, if this socialisation takes place in different cultural contexts then there will be different conceptions of gender roles which will then affect how 
gender is performed and perceived, creating social friction when different views clash. To alleviate issues that were thought to arise from residents being from different cultural backgrounds, female workers would directly ask about their background and building a rapport with them through this was seen as a good strategy in which to overcome lack of engagement.

Other strategies included having a discussion around lack of engagement with the resident and making it clear that it was not always possible to have a male worker. If a resident had a problem with the gender of a member of staff, it was agreed across the sample that there would be attempts to resolve it before it resulted in changing the member of staff. This suggests that due to gendered power relations in different cultures and worldviews, female participants sometimes felt hindered in forming a professional relationship with some residents due to their perceived view of women. It was felt that if this was not challenged it hindered the female workers' abilities to conduct their practice in a way that it would not have hindered male workers. However, it must be acknowledged that this does not incorporate the views of the male residents, and so that is something that needs to be explored in further research.

Three of the seven male participants felt they had to be more cautious when working with female residents and forming relationships with them. There were concerns with appearing intimidating or female residents feeling uncomfortable, similar to the concerns raised by the male student in Harding (2002). Several suggested that reasons for this behaviour was in case the women had previously been abused. Male workers being sexually harassed was also mentioned, and it was specified in one interview that these advances generally happened in residents' rooms. Responses to these perceived risks involved not going into a female resident's room alone - unless in extreme circumstances like suicide prevention - or making sure they were able to be monitored at all times when with a female resident. Whilst this affected how they conducted their practice, gendered power dynamics and implications for professional identities were not mentioned to as great an extent as they were by the female participants.

There was a strong theme across nine of the fifteen interviews that residents would generally display less aggressive behaviours towards female workers than they would male workers (depending on the resident's level of sobriety). Participants mainly viewed female workers as being seen as less threatening to aggressive residents and male workers being seen more as a challenge and more likely to inspire an aggressive response from residents. This corroborates the findings in Zufferey (2009) and from this it was felt that females were more proficient at de-escalating argumentative situations with male residents than their male counterparts. This was summed up by Margaret where she reflects on how her male colleague described the results of a man trying to de-escalate an aggressive situation with a male resident compared to a woman:

He always said it was like a lion stepping up to like another lion, and they're... they're trying to sort of fight for top dog, and so where he says basically if a female was there they're able to calm them down a lot better. Em, because nine times out of ten a male won't strike a female, where if it was a male on male there's a high percentage of there being a fight. Where if it's a female then, they'll either just walk away, or they'll just, eh, calm down. (Margaret)

As indicated by Margaret, women being able to de-escalate arguments more easily can be linked to this gendered view that "you don't hit a girl" (Michael) and "there's still this mind set among most of them that you shouldn't hit a woman" (Elizabeth). From these three quotes it can be implied that residents held perceptions of women as being non-threatening. From this implication, female participants or colleagues of participants used their knowledge of this general perception of their gender and this aspect of their 'self' (Davies, 1994) to help deescalate situations if there was time/staff to react in that strategic manner. Although it needs to 
be noted that this is only inferred as no interviews with residents were undertaken, and so this is another potential avenue for future research.

\section{Age and Gender:}

Age and gender were thought to work in tandem in terms of approachability. Similar to the findings in Zufferey (2009), it was suggested by seven participants that older women could be perceived by residents as mother figures. It was mentioned that some female members of staff then adopted a mothering role unconsciously:

Sometimes, em, the dynamic in where the resident will be treating the female, specially an older female, key worker, em, as a kinda mother figure, um... and that's something that, that needs to be guarded against from the keyworker's point of view who may slip into that role. (Peter)

This was regarded as problematic for both the resident and the female member of staff, as it did not encourage empowerment and led to greater dependency on that member of staff. Whilst this situation is not always the case, this suggests that the discourse of being older and female, and as such potentially being perceived as motherly, can then impede practice and relationships. Furthermore, this maternalistic behaviour was reported to cause tensions and inequalities between workers and residents. This highlights gender intersecting with age (Crenshaw, 1989: Crenshaw, 1991) to create workplace inequality through the social expectation that older women are 'motherly' (Butler, 1999) resulting in their unconscious acceptance of higher levels of caring responsibility. In some scenarios it was mentioned that sometimes other staff members had to step in and discourage that relationship. Although it was also possible that the female member of staff would realise and end that part of the relationship herself, explicitly emphasising their professional role and relationship to override the parental one it was thought the resident had created for the staff member.

Age:

Eight participants noted that workers being a similar age to residents made it easier to build relationships which aided the support that could be offered. However, whilst building a relationship more easily due to shared age can be perceived by workers as beneficial for the resident, it also had limitations. A number of the participants expressed the opinion that because younger staff members found it easier to build a rapport with younger residents, they had to be careful not be perceived by the resident as their friend but as a professional member of staff:

And then with the younger people... you can't think in an older mind set, I'm not, I'm not your contemporary, I am a staff member. Um... and... and I guess with boundaries, I'm not here to be your friend, I'm here to be a staff member, and your support worker. Em, sometimes, sometimes you can forget, y'know? Sometimes it's, it's yeah... you have to catch yourself and know that there's a boundary here. (Elizabeth)

Therefore, it was also suggested that participants recognised the need to have a selfawareness about how their identity and 'self' (Davies, 1994) could be perceived. It was suggested that having this awareness would aid them in maintaining their professional identity so that the relationship continued to be beneficial and not detrimental to practice. Similar issues 
between older members of staff and older residents were not mentioned by any participants.

In regards to older workers, seven participants felt that younger residents had issues relating to the older worker due to the perceived age disparity:

It's an age gap that you have to work at sort of covering and... I mean from, from their point of view they might think "there's no way I can relate to this person, he's much older than me, he's older than my dad." So there's a little bit of a barrier there, but, whatever, you should use your professional skill to work away with it. (Barry).

If generational differences between worker and resident created misunderstandings or confusion, some workers would ask the resident to explain as a way of breaking down this barrier. This then aided relationship building. Other strategies employed were for participants to find out about the resident's interests and research them so that they had some common ground to form a relationship. Playing pool as well as other activities - e.g. music nights, watching TV etc. - also provided opportunities for workers to challenge the barriers that they felt perceptions of their age created, and actively build a rapport with residents of differing ages. Older participants then actively performed impression management (Goffman, 1959), altering their 'self' (Davies, 1994) through their personal front of age to present a different version of themselves than they had initially in order to aid building rapport. Therefore older workers had to work at familiarity and approachability to build rapport with younger service users. However, younger workers had to actively manage over familiarity for this same group.

Participants' ages equating to their perceived levels of experience of work and life by both workers and residents was mentioned by 11 participants. Subsequently, younger participants, such as those in their 30s and below, reported being perceived as inexperienced due to their age and appearance of being young. This sometimes led to their advice being dismissed by residents who were older than them. Older workers were generally thought in this study as having more experience and authority, backing up the stereotype of older people being regarded as more dominant (Masip et al, 2004), and this made it easier to create professional relationships with residents and not be challenged as in the case of younger workers. Younger workers addressed the perception of inexperience and lack of authority through proving themselves and their knowledge of the sector:

That I'm acting older than I am.... Em... it's a little bit about authority, I guess in that I do take authority, I am... at times an authority figure, y'know when I'm in charge and I tell them to do something I mean it, and they know I mean it. So it's about body language, how I use my voice, eye contact, the physicality of those situations, I'm not cowering away from them, I'm not speaking in whispers, not scared to stand up, and stand up to them, just cause they're older than me or bigger than me. I'm the one with the authority and I'm going to use it. I'm absolutely bricking it on the inside, but I've got a job to do. (Elizabeth

It can be implied that this participant was then intentionally putting on a front (Goffman, 1959) and using their 'self' in the form of their body language (Davies, 1994) and other aspects of their personal fronts, e.g. voice, eye contact etc., to assert authority, despite the fact they were younger than the resident. It was thought that once the worker had proved themselves through demonstrating that they had sufficient knowledge of the sector and enforced their authority, then age was not felt to be as great a barrier to their practice and rapport building. 


\section{Background:}

Background was perceived to consist of many things in this sample, however, what became most apparent during analysis was nationality, upbringing, faith, and socioeconomic background. Having similar backgrounds or experiences to the residents and other workers was seen by over two thirds of the participants as benefiting building relationships. It was thought that residents might view themselves as being able to have a better relationship with a worker through having commonalities. Participants would utilise their 'self' (Davies, 1994) and draw upon these similar experiences or exaggerate commonalities in their backgrounds to generate an impression that aided building rapport:

Margaret: Em... often when I'm chatting with the residents, em, they'll sort of say "you don't know what it means to be brought up in a housing scheme" and things like that, and I'll say "actually I do, I was brought up in a housing scheme" em, so culturally, like that, I can relate to the service users and they can then relate to me because of where I was brought up. Em, so that often helps.

Int: So it's kind of like having a common ground?

Margaret: Yeah, yeah. [...] they're quite good at saying "oh well actually you do know what it's like to be brought up in a housing scheme" [...] I think it bonds the relationship. Em, cause often they'll say 'aye you know what you're talking about" and things like that. (Margaret)

Although on the whole those who took this approach were careful not to divulge too much about their personal life to preserve their professional identity and to prevent potentially harming the resident with oversharing.

Five participants mentioned socio-economic background affecting their ability to build rapport, with three from lower socio-economic backgrounds feeling it was easier than two who were from high socio-economic backgrounds who felt they were perceived as being harder to relate to. Once common ground had been found in interests and backgrounds then building relationships was regarded by the workers as being a lot easier. Asking residents and other colleagues (generally perceived to be from low socio-economic backgrounds) if there was confusion around things such as colloquial language was also seen as a good strategy in building rapport. Language also acted as an important method of connecting to residents, with three participants adopting different language (e.g. more colloquial) and/or accents to try and identify more with residents:

I think I can, maybe without realising it even, put on a bit more of a rougher Scottish accent when I'm interacting with people so em, like, yeah, I think to identify with them and to, to feel culturally relevant to the way that they're talking. I think I can sometimes be, I can try and participate in that with them a bit, $[\ldots]$ so they can be like "okay she gets my language" or "she gets my kind of a..." and I don't think I necessarily do it consciously all the time, I think sometimes I do it subconsciously, I think my accent just changes a little bit (Fiona)

In this sense adopting this language and accent created the impression of understanding at a personal level which then aided the participant in conducting their practice through being taken more seriously. This method of changing one's personal front (Goffman, 1959) and 
adapting their 'self' (Davies, 1994) was adopted by numerous participants. In this instance using different types of language allowed workers to negotiate how their identity (e.g. socioeconomic background) was perceived by residents to aid building a positive relationship.

\section{Conclusion:}

Overall, this research has demonstrated that identities are multifaceted and complex, produced not only by the individuals themselves, but in cooperation with the individuals they interact with (Butler, 1999: Crenshaw, 1991). Whilst presented largely as separate here for clarity, gender, age and background do not work in isolation, instead they amalgamate to generate a resident's perception of a worker, and whilst this impression may not be accurate it can significantly hinder positive relationship building in an already challenging environment.

It has been recognised in the findings that workers can control the impression they exude to an extent as Goffman (1959) advocated and use their identity to build rapport with residents as discussed in the 'use of self' literature (Davies, 1994). Front alteration (Goffman, 1959) was thought to aid positive relationship building and thus more effectively help residents through homelessness. However, changing the impression that, it is believed, others have of you is difficult and will be hindered by their preconceived notions of your identity, particularly those derived from stereotypes or discourses already embedded within society (Goffman, 1959: Butler, 1999: Abrams et al, 2015: Masip et al, 2004). Whilst no residents were interviewed in this work making it impossible to tell if, for example, male residents were genuinely flirting with female workers, it does not negate the way it made the female workers feel and react. Relationships are two-way streets and if workers do not feel comfortable, regardless of the residents' motivations, that can also alter how they interact with residents in future and make building positive relationships difficult.

Balancing the boundaries of worker-resident interaction and their personal and professional identities is challenging, and whilst this was raised in Zufferey (2009) and Harding (2002), this study has revealed further issues workers can experience due to identity and the strategies they use to overcome them. Whilst this study cannot be said to be exhaustive of the homelessness sector, the findings give insights into the complexities of supporting people who are homeless. These issues require further investigation but this article aims to provide a starting point. The key implication from this is that more targeted training - e.g. including role playing scenarios - should be offered to prepare workers for challenging situations that can arise from these interpretations of identities. At present there is no mandatory training in this area in the homelessness sector in Scotland. However, modifying one's behaviour and expression of identity is only possible if one is conscious of it and how best to modify it will depend on the context, so self-awareness and reflection around potential perceptions of their identities and how they can impact relationships needs to be encouraged amongst homelessness workers. The theories discussed provided a valuable framework in understanding identity management within the data and enabled more insights in what is already an under-theorised and under-researched area. As training in Scotland is limited for homelessness workers it is suggested that in future these theories could be adapted further into training tools to highlight identity management in a non-personal way and provide practitioners a language in which to discuss it. The importance of relationships and building rapport needs to be acknowledged if homelessness services are to improve not only the support that they give to people who are homeless, but also the support that they give to their own workforce. This study has contributed to this area through identifying sites where identity management can be required, the strategies workers can use to cope with negative interactions, and suggested theories for understanding the identity management taking place. This study evidences ongoing issues homelessness workers face in conducting their practice. To enable more focused training to alleviate some of 
the issues discussed in this research, more investigation into the perceptions people who are homeless have of workers' identities, and how these perceptions impact their experiences, is required. It is also imperative that if training is developed and delivered, that it is then evaluated to determine how effective it has been in impacting practice and promoting positive relationship building. It is through this continued investigation and workforce development, acknowledging the roles of both workers and people who are homeless, that true advances and improvements might be made.

\section{Acknowledgements}

Will be added after blind review.

\section{Funding}

This work was supported by the Economic and Social Research Council.

\section{References:}

Abrams, D., Swift, J, H., Lamont, A, R., Drury, L. 2015. The barriers to and enablers of positive attitudes to ageing and older people, at the societal and individual level [pdf] Available at

https://www.gov.uk/government/uploads/system/uploads/attachment_data/file/454735/gs-1515-future-ageing-attitudes-barriers-enablers-er06.pdf

Anderson, I. and Serpa, R. 2013. The Right to Settled Accommodation for Homeless People in Scotland: A Triumph of Rational Policy Making? European Journal of Homelessness, 7 (1), pp.13-39

Beresford, P. Croft, S. Adshead, L. (2008) 'We Don't See Her as a Social Worker': A Service User Case Study of the Importance of the Social Worker's Relationship and Humanity. The British Journal of Social Work, 38(7), pp. 1388-1407

Bhui, K., Shanahan, L., Harding, G. 2006. Homelessness and Mental Illness: A literature review and a qualitative study of perceptions of the adequacy of care. International Journal of Social Psychiatry, 52 (2), pp.152-165.

Bryman, A. (2012) Social Research Methods Fourth Edt Oxford: Oxford University Press

Butler, J. 1999. Gender Trouble: Feminism and the Subversion of Identity. London: Routledge.

Christie, A. 2006. Negotiating the uncomfortable intersections between gender and professional identities in social work. Critical Social Policy, 26 (2), pp.390-411

Crenshaw, K. 1989. Demarginalizing the Intersection of Race and Sex: A Black Feminist Critique of Antidiscrimination Doctrine, Feminist Theory and Antiracist Politics. University of Chicago Legal Forum, (7), pp. 139-168.

Crenshaw, K 1991. Mapping the Margins: Intersectionality, Identity Politics, and Violence against Women of Color. Stanford Law Review, 43 (6), pp. 1241-1299 
Centre for Economic and Social Inclusion 2006. The role of housing providers in enabling homeless people's employment success [pdf] Available at: https://kipdf.com/the-role-ofhousing-providers-in-enabling-homeless-people-s-employmentsuccess_5ac2eb6b1723dde88f3a10aa.html

Crown 1977. Housing (Homeless) Persons Act 1977 [pdf] Available at: http://www.legislation.gov.uk/ukpga/1977/48/pdfs/ukpga_19770048_en.pdf

Crown 2010. Housing (Scotland) Act 2010 [pdf] Available at: http://www.legislation.gov.uk/asp/2010/17/pdfs/asp_20100017_en.pdf

Davies, M. (1994) Essential Social Worker: An Introduction to Professional Practice in the 1990s. England: Ashgate Publishing Limited.

De Boer, C. and Coady, N. (2006) Good helping relationships in child welfare: learning from stories of success. Child and Family Social Work, (12), pp. 32-42

Eisenchlas, A, S. 2013. Gender Roles and Expectations: Any Changes Online? SAGE Open, 3 (4), pp. 1-11

Farrimond, H. 2013. Doing Ethical Research. UK: Palgrave MacMillan.

Fitzpatrick, S., Kemp, P., Klinker, S. 2000. Single homelessness: An overview of research in Britain. Great Britain: Polity Press.

Goffman, E. 1959. The Presentation of Self in Everyday Life. USA: Penguin Group.

Gordon, J. and Dunworth, M. (2017) The fall and rise of 'use of self'? An exploration of the positioning of use of self in social work education. Social Work Education, 36(5), pp. 591-603

Harding, J. 2002. Talking about Homelessness: a teaching and research initiative in East London. Teaching in Higher Education, 7(1), pp. 81-95

Huey, L. and Berndt, E. 2008. 'You've gotta learn how to play the game': homeless women's use of gender performance as a tool for preventing victimization. Sociological Review, 56 (2), pp.177-194

Jardine, L. and Bilton, K. 2006. Knowledge, Understanding and Views of Homelessness amongst Service Providers [pdf] Social Research Development Department. Available at: http://www.gov.scot/Resource/Doc/128897/0030702.pdf

Langlotz, A. 2015. Creating Social Orientation Through Language: A socio-cognitive theory of situated social meaning. USA: John Benjamins Publishing Co.

Lund, B. 2011. Understanding Housing Policy Second Edt. Great Britain: Policy Press

Manthorpe, J., Cornes, M., O’Halloran, S., Joly, L. 2013. Multiple Exclusion Homelessness: The Preventive Role of Social Work. British Journal of Social Work, 45 (2), pp. 587-599 
Masip, J., Garrido, E., Herrero, C. 2004. Facial appearance and impressions of 'credibility': The effects of facial babyishness and age on person perception. International Journal of Psychology, 39 (4), pp. 276-289

Mathews B. and Ross, L. 2010. Research Methods: A practical guide for the social sciences. UK: Pearson Education Limited.

McCarthy, L. 2013. Homelessness and identity: a critical review of the literature and theory. People, Place and Policy Online, 7 (1), pp. 46-58

Robinson, P. 2008. Working with Young Homeless People. London: Jessica Kingsley Publishers.

Scottish Government 2005. Code of Guidance on Homelessness [pdf] Scottish Government. Available at: http://www.gov.scot/Resource/Doc/53814/0012265.pdf

Scottish Government 2013. Operation of the Homeless Persons Legislation in Scotland: $2012-$ 13 [pdf] Scottish Government. Available at: http://www.gov.scot/Resource/0043/00434119.pdf

Snow, A, D. and Anderson, L. 1987. Identity Work Among the Homeless: The Verbal Construction and Avowal of Personal Identities. American Journal of Sociology, 92 (6), pp. 1336-1371

SRA 2003. Ethical Guidelines [pdf] Available at: http://the-sra.org.uk/wpcontent/uploads/ethics03.pdf

Stevenson, C. 2013. A qualitative exploration of relations and interactions between people who are homeless and use drugs and staff in homeless hostel accommodation. Journal of Substance Use, 19 (1-2), pp.134.140

Zufferey, C. 2009. Making Gender Visible Social Work Responses to Homelessness. Journal of Women and Social Work, 24 (4), pp.382-393

Zufferey, C. 2015. Chapter 6: Intersectional Feminism and Social Work Responses to Homelessness in Wahab, S. Anderson-Nathe, B. Gringeri, C. eds. (2015) Feminisms in Social Work Research: Promise and Possibilities for Justice-based Knowledge. London: Routledge. 